\title{
Use of mathematic modeling to compare and predict hemodynamic effects of the modified Blalock-Taussig and right ventricle-pulmonary artery shunts for hypoplastic left heart syndrome
}

\author{
Edward L. Bove, MD, ${ }^{a}$ Francesco Migliavacca, PhD, ${ }^{\mathrm{b}}$ Marc R. de Leval, MD, ${ }^{\mathrm{c}}$ Rossella Balossino, PhD, \\ Giancarlo Pennati, PhD, ${ }^{\mathrm{b}}$ Thomas R. Lloyd, MD, ${ }^{\mathrm{a}}$ Sachin Khambadkone, MD, ${ }^{\mathrm{c}}$ Tain-Yen Hsia, MD, ${ }^{\mathrm{c}}$ and \\ Gabriele Dubini, $\mathrm{PhD}^{\mathrm{b}}$
}

Supplemental material is available online.
From the Section of Cardiac Surgery, ${ }^{a}$ the University of Michigan School of Medicine, Ann Arbor, Mich; the Laboratory of Biological Structure Mechanics, Department of Structural Engineering, ${ }^{\mathrm{b}}$ Politecnico di Milano, Milan, Italy; and the International Congenital Cardiac Center and Cardiothoracic Unit, ${ }^{\mathrm{c}}$ Great Ormond Street Hospital for Children NHS Trust, London, United Kingdom.

Received for publication March 1, 2007; revisions received March 23, 2007; accepted for publication April 9, 2007.

Address for reprints: Edward L. Bove, MD, F 7830 Mott Children's Hospital, 1500 East Medical Center Dr, University of Michigan, Ann Arbor, MI 48109-0223 (E-mail: elbove@umich.edu).

J Thorac Cardiovasc Surg 2008;136:312-20 $0022-5223 / \$ 34.00$

Copyright $(\subset 2008$ by The American Association for Thoracic Surgery

doi:10.1016/j.jtcvs.2007.04.078
Objective: Stage one reconstruction (Norwood operation) for hypoplastic left heart syndrome can be performed with either a modified Blalock-Taussig shunt or a right ventricle-pulmonary artery shunt. Both methods have certain inherent characteristics. It is postulated that mathematic modeling could help elucidate these differences.

Methods: Three-dimensional computer models of the Blalock-Taussig shunt and right ventricle-pulmonary artery shunt modifications of the Norwood operation were developed by using the finite volume method. Conduits of 3,3.5, and $4 \mathrm{~mm}$ were used in the Blalock-Taussig shunt model, whereas conduits of 4, 5, and 6 $\mathrm{mm}$ were used in the right ventricle-pulmonary artery shunt model. The hydraulic nets (lumped resistances, compliances, inertances, and elastances) were identical in the 2 models. A multiscale approach was adopted to couple the 3 -dimensional models with the circulation net. Computer simulations were compared with postoperative catheterization data.

Results: Good correlation was found between predicted and observed data. For the right ventricle-pulmonary artery shunt modification, there was higher aortic diastolic pressure, decreased pulmonary artery pressure, lower Qp/Qs ratio, and higher coronary perfusion pressure. Mathematic modeling predicted minimal regurgitant flow in the right ventricle-pulmonary artery shunt model, which correlated with postoperative Doppler measurements. The right ventricle-pulmonary artery shunt demonstrated lower stroke work and a higher mechanical efficiency (stroke work/total mechanical energy).

Conclusions: The close correlation between predicted and observed data supports the use of mathematic modeling in the design and assessment of surgical procedures. The potentially damaging effects of a systemic ventriculotomy in the right ventriclepulmonary artery shunt modification of the Norwood operation have not been analyzed.

$O$ urvival for the staged surgical reconstruction for hypoplastic left heart syndrome (HLHS) has continued to improve. Although there are many reasons for this improvement, better understanding of the complex physiology in the single-ventricle patient is a major factor. In the classic Norwood operation for HLHS, pulmonary blood flow is provided through a systemic pulmonary artery shunt intended to restrict flow and balance the systemic and pulmonary blood flows. However, a well-recognized immutable disadvantage of this circulation is that pulmonary blood flow occurs throughout the cardiac cycle. The resultant diastolic run-off might therefore lead to pulmonary overcirculation, low diastolic blood pressure, and unacceptable levels of right ventricular volume overload. It has also been postulated that 

Abbreviations and Acronyms
$\mathrm{AoA}=$ ascending aorta
AoD $=$ descending aorta
BTS = Blalock-Taussig shunt
$\mathrm{CO}=$ cardiac output
3-D = 3-dimensional
HLHS $=$ hypoplastic left heart syndrome
IA $=$ innominate artery
LCA = left carotid artery
LSA = left subclavian artery
RVS = right ventricle-pulmonary artery shunt
SVR = systemic vascular resistance

this arrangement might lead to decreased coronary blood flow, further aggravating a right ventricle that is subjected to increased wall stress.

Recently, a modification of the Norwood procedure has been introduced in an attempt to avoid some of the adverse hemodynamic consequences inherent in a systemic-pulmonary artery shunt. Although this concept was presented many years ago by Norwood and colleagues, ${ }^{1}$ the technique of interposing a conduit between the right ventricle and the pulmonary arteries was reintroduced and recently reported by Imoto and coworkers ${ }^{2}$ and subsequently by Sano and colleagues. ${ }^{3}$ These groups, in addition to others, ${ }^{4-9}$ reported improved survival when compared with historical controls from their own centers. Controversy remains, however, regarding the potential salutary effects of this modification, and few data exist to substantiate the superiority of either approach.

Computer flow modeling has been used to examine the hemodynamic effects of a number of surgical operations. In particular, this investigative tool has been beneficial in elucidating the optimal approach to the staged reconstruction of the single ventricle. ${ }^{10-15}$ In an effort to examine the effects of both the modified Blalock-Taussig shunt (BTS) and the right ventricle-pulmonary artery shunt (RVS) as a part of the Norwood operation for HLHS, mathematic models of both techniques were developed.

\section{Materials and Methods}

\section{Three-dimensional Models}

Two different 3-dimensional (3-D) detailed models of the Norwood procedure based on the finite volume method were developed (Figure 1): an RVS modification and an innominate artery (IA)-pulmonary artery or modified BTS modification. Sizes of the conduits were 4,5 , and $6 \mathrm{~mm}$ for the RVS model and 3, 3.5, and $4 \mathrm{~mm}$ for the BTS model.

The geometric dimensions of the blood vessel were taken from angiograms from a group of patients with a modified BTS performed during catheterization before the second-stage reconstructive operation. ${ }^{16}$ The RVS model was created for the same anatomy. Both models (Figure 1) include the ascending aorta (AoA) and descending aorta (AoD) with the 3 brachiocephalic vessels: left subclavian artery (LSA), left carotid artery (LCA), and IA. The main coronary artery branches from the AoA. The right pulmonary artery and left pulmonary artery are also represented. These models exhibit 1 or 2 upstream sections, which included the AoA for the BTS modification and the AoA plus the shunt for the RVS modification, and 7 downstream sections (AoD, LSA, LCA, IA, main coronary artery, left pulmonary artery, and right pulmonary artery). Meshes were developed that included approximately 130,000 4-node tetrahedral elements. The implicit backward Euler method was used as the time integration technique, implementing a fixed time increment equal to $10^{-4}$ seconds. A segregated solver was chosen. Four cardiac cycles were simulated for each model to guarantee a stable solution. The boundary conditions are presented in Appendix E1. ${ }^{12}$ The Fluent general-purpose fluid dynamic code (Fluent, Inc, Lebanon, $\mathrm{NH}$ ) was used for calculations.

\section{Lumped Parameter Models}

The circulatory network outside the surgical region was taken into account by means of a lumped parameter model built on the basis of data from 28 patients submitted to catheterization before stage 2 surgical reconstruction. ${ }^{16}$ The lumped parameter model of the BTS modification was built according to the methodology previously adopted to model the fetal ${ }^{13}$ and neonatal ${ }^{14,16}$ circulations. The model is made of 4 subsystems: heart, systemic, pulmonary, and coronary circulations. A model defined in a previous study from our laboratory was used for the heart. ${ }^{14}$ Time-varying elastances were used to model the right and left atria and single ventricle. Nonlinear resistances were adopted to describe the ventricular outflow and inflow valves, whereas a linear term models a nonrestrictive atrial septal defect. The systemic circulation was divided into 7 compartments describing the arterial and venous districts located in the upper and lower body. Four compartments defined the left and right pulmonary arterial and venous beds. According to the study by Mantero and colleagues, ${ }^{17} 4$ blocks were used to represent the coronary circulation, where the intramyocardial pressure is reproduced by means of a pressure generator controlled by the single-ventricle pressure. Values of the adopted parameters can be found in a previous study from our laboratory. ${ }^{10}$

The main assumptions for all mathematic models are as follows ${ }^{16}$ : body surface area of $0.33 \mathrm{~m}^{2}$, pulmonary vascular resistance of $2.3 \mathrm{~mm} \mathrm{Hg} \cdot \mathrm{m}^{-2} \cdot \mathrm{L}^{-1} \cdot \mathrm{min}^{-1}$, systemic vascular resistance (SVR) of $21.6 \mathrm{~mm} \mathrm{Hg} \cdot \mathrm{m}^{-2} \cdot \mathrm{L}^{-1} \cdot \mathrm{min}^{-1}$, heart rate of 120 beats/min, hemoglobin value of $16.52 \mathrm{~g} / \mathrm{dL}$, oxygen consumption of $156.83 \mathrm{~mL} \cdot \min ^{-1} \cdot \mathrm{m}^{-2}$, and pulmonary vein saturation of 98\%. Oxygen calculations are presented in Appendix E1.

\section{Multiscale Models}

A multiscale approach ${ }^{18}$ was adopted to couple the 3-D models with the lumped model, as described in detail in Appendix E1. ${ }^{12}$ The finite volume method was adopted for the 3-D models to solve the mass and momentum conservation equations for an incompressible Newtonian fluid (Navier-Stokes equations), whereas the lumped parameter model is described by a nonlinear algebraic differential equation system containing forcing terms caused by interface conditions with the 3-D finite volume method model. Figure 1 shows the BTS and RVS coupled models. All simulations were carried out on a Pentium IV $2.8 \mathrm{GHz}$ personal computer. Time required for the simulation of a cardiac cycle was about 12 hours. 


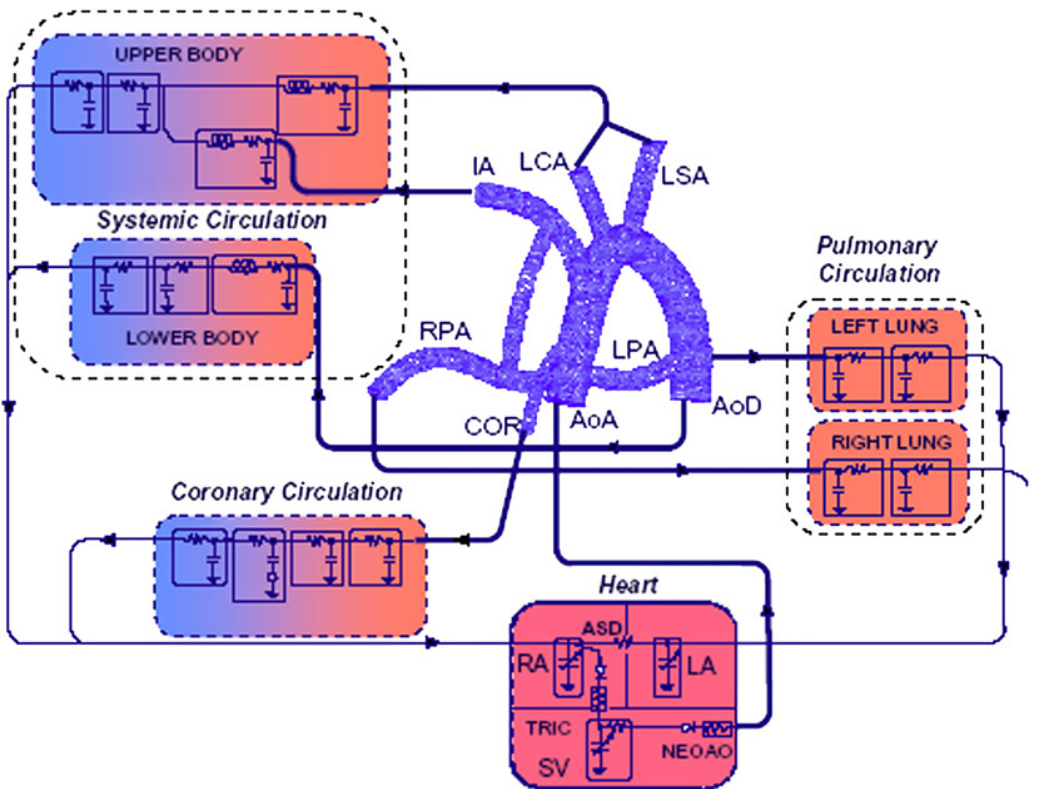

BTS Model

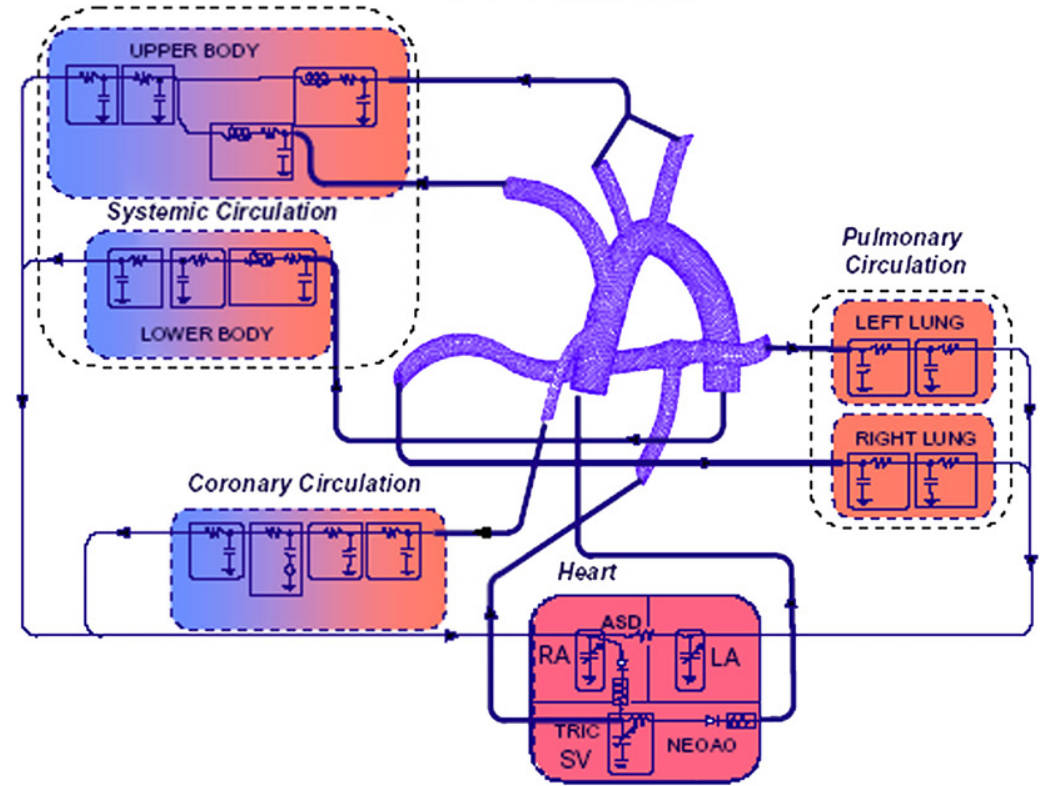

Figure 1. Coupled models: Blalock-Taussig shunt (BTS; top) and right ventricle-pulmonary artery shunt (RVS; bottom). Three-dimensional models of the BTS and RVS models include the ascending aorta $(A o A)$, descending aorta $(A o D)$, coronary artery (COR), innominate artery (IA), left carotid artery (LCA), left subclavian artery (LSA), left pulmonary artery (LPA), and right pulmonary artery (RPA). RA, Right atrium; ASD, atrial septal defect; $L A$, left atrium; TRIC, ventricular inflow valve; NEOAO, ventricular outflow valve; $S V$, single ventricle.

\section{RVS Model}

\section{Results}

Data available in the literature regarding the RVS modification of the Norwood procedure are limited because of the recent introduction of this surgical modification. Clinical quantitative hemodynamic data on patients undergoing the Norwood procedure with an RVS have been reported by a number of groups. ${ }^{5-9}$ These data are summarized in Table 1 , together with the most relevant results from RVS and BTS mathematic models, which include systolic and diastolic pressure at the interfaces of the 3-D model (AoA and pulmo- nary arteries), cardiac output (CO), pulmonary-to-systemic flow ratio (QP/QS), coronary blood flow, percentage flow to the right and left lungs, arterial and venous oxygen saturation, oxygen delivery, arteriovenous difference, ejection fraction, and cardiac mechanical efficiency (stroke work/total mechanical energy). QS is evaluated as the sum of LSA, LCA, IA, AoD, and main coronary artery flows.

Comparing the arterial oxygen saturations in the models with a conduit of $4 \mathrm{~mm}$, the BTS model showed higher values than the RVS model $(80.4 \%$ vs $67.1 \%)$. A larger conduit size 
TABLE 1. Results from the RVS and BTS models with effects of changes in PVR and SVR for the RVS model with a 6-mm conduit

\begin{tabular}{|c|c|c|c|c|c|c|c|c|}
\hline \multirow[b]{2}{*}{ Variable } & \multicolumn{8}{|c|}{ Mathematic models } \\
\hline & \multicolumn{3}{|c|}{ RVS } & \multicolumn{3}{|c|}{ BTS } & \multirow{2}{*}{$\begin{array}{c}\text { RVS } \\
6 \text { mm } \\
\text { SVR }=10.8 \\
\text { PAR }=2.3\end{array}$} & \multirow{2}{*}{$\begin{array}{c}\text { RVS } \\
6 \mathrm{~mm} \\
\text { SVR }=21.6 \\
\text { PAR }=4.6\end{array}$} \\
\hline $\begin{array}{l}\text { Shunt diameter } \\
\text { Resistances }\end{array}$ & $4 \mathrm{~mm}$ & $\begin{array}{c}5 \mathrm{~mm} \\
\mathrm{SVR}=21.6 \\
\mathrm{PAR}=2.3\end{array}$ & $6 \mathrm{~mm}$ & $3 \mathrm{~mm}$ & $\begin{array}{c}3.5 \mathrm{~mm} \\
\mathrm{SVR}=21.6 \\
\mathrm{PAR}=2.3\end{array}$ & $4 \mathrm{~mm}$ & & \\
\hline Aortic systolic pressure (mm Hg) & 115.8 & 111.0 & 107.2 & 118.2 & 115.0 & 111.4 & 99.0 & 109.1 \\
\hline Aortic diastolic pressure (mm Hg) & 71.6 & 68.3 & 65.7 & 56.8 & 48.7 & 45.6 & 43.9 & 67.1 \\
\hline Pulse pressure $(\mathrm{mm} \mathrm{Hg})$ & 44.2 & 42.7 & 41.5 & 61.3 & 66.3 & 65.8 & 55.2 & 42.0 \\
\hline RV systolic pressure (mm Hg) & 122.9 & 117.6 & 113.4 & 131.4 & 129.3 & 126.4 & 109.5 & 115.6 \\
\hline RV diastolic pressure (mm Hg) & 4.12 & 4.18 & 4.24 & 5.10 & 5.40 & 5.68 & 5.28 & 4.27 \\
\hline PA pressure, mean $(\mathrm{mm} \mathrm{Hg})$ & 8.5 & 11.0 & 12.7 & 9.8 & 11.9 & 13.5 & 13.2 & 18.4 \\
\hline Qp/Qs ratio & 0.57 & 0.84 & 1.05 & 0.72 & 1.00 & 1.26 & 0.69 & 0.85 \\
\hline $\mathrm{CO}(\mathrm{L} / \mathrm{min})$ & 2.09 & 2.31 & 2.46 & 2.12 & 2.28 & 2.38 & 2.90 & 2.28 \\
\hline Pulmonary blood flow (L/min) & 0.76 & 1.05 & 1.26 & 0.89 & 1.14 & 1.33 & 1.18 & 1.05 \\
\hline Systemic blood flow (L/min) & 1.33 & 1.26 & 1.20 & 1.23 & 1.14 & 1.05 & 1.72 & 1.23 \\
\hline Conduit backward flow (\%) & 6.07 & 2.38 & 2.95 & - & - & - & 3.14 & 6.22 \\
\hline Coronary blood flow (L/min) & 0.089 & 0.084 & 0.081 & 0.081 & 0.076 & 0.071 & 0.060 & 0.083 \\
\hline Coronary perfusion pressure $(\mathrm{mm} \mathrm{Hg})$ & 67.4 & 64.1 & 61.5 & 51.7 & 43.3 & 39.9 & 38.6 & 62.8 \\
\hline $\mathrm{EF}(\%)$ & 55.6 & 61.3 & 65.3 & 50.0 & 52.5 & 54.1 & 69.0 & 59.1 \\
\hline Mechanical efficiency & 0.80 & 0.85 & 0.88 & 0.75 & 0.78 & 0.85 & 0.91 & 0.85 \\
\hline $\mathrm{O}_{2}$ delivery $\left(\mathrm{mL} \cdot \mathrm{min}^{-1} \cdot \mathrm{m}^{-2}\right)$ & 600.2 & 640.0 & 640.0 & 593.6 & 590.5 & 566.9 & 902.7 & 626.8 \\
\hline Sat $_{\text {ven }}(\%)$ & 49.6 & 57.2 & 60.0 & 52.7 & 56.9 & 58.1 & 64.7 & 56.8 \\
\hline Sat $_{\text {art }}(\%)$ & 67.1 & 75.8 & 79.5 & 71.7 & 77.5 & 80.4 & 78.3 & 75.7 \\
\hline $\mathrm{A}-\mathrm{V} \mathrm{O}_{2}$ & 17.5 & 18.6 & 19.5 & 19.0 & 20.6 & 22.3 & 13.6 & 18.9 \\
\hline
\end{tabular}

$R V S$, Right ventricle-pulmonary artery shunt; $B T S$, Blalock-Taussig shunt; $P V R$, pulmonary vascular resistance; $S V R$, systemic vascular resistance; $P A R$, pulmonary arteriolar resistance; $R V$, right ventricular; $P A$, pulmonary artery; $C O$, cardiac output; $E F$, ejection fraction; $S a t_{\text {ven, }}$ oxygen saturation of the venous blood; Sat art oxygen saturation of arterial blood; $A-\mathrm{V}_{2}$, arteriovenous difference. * Statistically significant.

is needed in the RVS model to achieve equivalent arterial oxygen saturation. For this reason, hemodynamic outcome comparisons between the 2 modifications were done comparing small BTSs with larger RVSs (3-mm BTS vs 4-mm RVS, 3.5-mm BTS vs 5-mm RVS, and 4-mm BTS vs 6-mm RVS).

By using this comparison, the results demonstrated that the RVS model exhibited lower pulse pressure, lower QP/ QS ratio, lower pulmonary artery pressure, lower right ventricular systolic and diastolic pressures, and higher coronary perfusion pressure when compared with the BTS model at similar arterial oxygen saturation. These findings are consistent with clinical data reported in the literature (Table 1). The mathematic models also predicted behaviors that are not confirmed at the moment by clinical data, namely higher coronary blood flow in the RVS model.

Figure 2 (upper panel) depicts the shunt flow tracings in the RVS models. Pulmonary flow is mainly systolic, with minimal diastolic regurgitant flow. In the BTS model the shunt flow is always forward in concordance with the pulmonary pressure tracings (Figure 2, middle panel). The average pulmonary pressure values are slightly decreased in the RVS models, but the difference is minimal. In the RVS model the temporal tracing of the pulmonary pressure is highly pulsa- tile, with pulse pressures of up to $25 \mathrm{~mm} \mathrm{Hg}$ in systole, whereas in the BTS model it is nearly linear.

The presence of forward flow in the BTS model has been previously reported by our group ${ }^{11}$ and is confirmed by the present simulations. Figures 3 and 4 demonstrate the velocity profiles in different cross-sections of the BTS model with a 3.5-mm shunt and the RVS model with a 5-mm shunt at 4 points of the cardiac cycle. The main difference between these 2 simulations is that in the RVS model the flow is lower and there is reversal of flow during diastole. Furthermore, in the RVS model velocity profiles are skewed in the portion of the shunt near the ventricle and blunter near the pulmonary artery anastomosis (Figure 4). The ratio between the negative and positive velocity time integrals is about $7 \%$, whereas the same ratio evaluated for flow rate curve (Figure 2, middle panel) is 5.9\%. This indicates that the velocity Doppler tracings slightly overestimate the backward flow. The presence of backward flow is confirmed by our Doppler tracings (Figure 4, upper right) recorded in patients with a 5-mm RVS, as well as by Ohye and coworkers. ${ }^{19}$ The coronary blood flow was noted to be greater in the RVS model (Table 1).

The RVS models show higher values of oxygen delivery at equivalent arterial oxygen saturation. The BTS models 
TABLE 1. Continued

\begin{tabular}{|c|c|c|c|c|c|c|c|c|c|}
\hline \multicolumn{2}{|c|}{ Maher and coworkers ${ }^{4}$} & \multicolumn{2}{|c|}{ Malec and coworkers ${ }^{6}$} & \multicolumn{2}{|c|}{ Mair and coworkers ${ }^{5}$} & \multicolumn{2}{|c|}{ Januszewska and coworkers ${ }^{8}$} & \multicolumn{2}{|c|}{ Ghanayem and coworkers ${ }^{9}$} \\
\hline RVS & BTS & RVS & BTS & RVS & BTS & RVS & BTS & RVS & BTS \\
\hline $5 \mathrm{~mm}$ & $4 \mathrm{~mm}$ & $5 \mathrm{~mm}$ & $4 \mathrm{~mm}$ & $5 \mathrm{~mm}$ & $3.5 / 4 \mathrm{~mm}$ & $5 \mathrm{~mm}$ & $3.5 / 4 \mathrm{~mm}$ & $6 \mathrm{~mm}$ & $3 / 3.5 / 4 \mathrm{~mm}$ \\
\hline $95.6 \pm 13.5$ & $105.8 \pm 14.9$ & $88.3 \pm 17.2$ & $108.0 \pm 14.6$ & $65.2-73$ & $60.9-63.7$ & $100.5 \pm 31.7$ & $102.1 \pm 13.3$ & $67 \pm 8$ & $73 \pm 11$ \\
\hline $54.5 \pm 9.9$ & $41.5 \pm 10.9^{*}$ & $58.5 \pm 7.6$ & $51.6 \pm 9.5$ & $43.7-44.9$ & $33.9-34.9$ & $54.1 \pm 11.5$ & $50.3 \pm 7.4$ & $46 \pm 6$ & $39 \pm 4^{*}$ \\
\hline $43.2 \pm 12.9$ & $64.4 \pm 12.9 *$ & $29.8 \pm 10.1$ & $56.4 \pm 15.2^{*}$ & & & $46.6 \pm 27.7$ & $51.8 \pm 14.4$ & & \\
\hline $99.8 \pm 19.9$ & $110.4 \pm 17.3$ & $93.0 \pm 25.7$ & $115.3 \pm 16.7$ & & & $104.9 \pm 34.5$ & $109.5 \pm 16.2$ & & \\
\hline $9.16 \pm 2.4$ & $10.6 \pm 2.9$ & $10.17 \pm 2.7$ & $9.46 \pm 3.4$ & 11 & 12 & $9.77 \pm 3.5$ & $7.79 \pm 4.0$ & & \\
\hline $12.8 \pm 2.3$ & $16.6 \pm 3.74^{*}$ & & & 13 & 14 & & & & \\
\hline $0.92 \pm 0.5$ & $1.42 \pm 0.36^{*}$ & $0.68 \pm 0.4$ & $1.41 \pm 0.7^{*}$ & 0.9 & $1.6^{*}$ & $0.80 \pm 0.47$ & $1.24 \pm 0.43^{*}$ & $1.8 \pm 1.2$ & $1.7 \pm 0.8^{*}$ \\
\hline
\end{tabular}

$46 \pm 10.1 \quad 32 \pm 10.3^{*}$

\begin{tabular}{llllllllll}
$50.4 \pm 7.4$ & $46.9 \pm 7.4$ & $47.2 \pm 2.8$ & $49.4 \pm 7.3$ & 49 & 51 & $43.5 \pm 6.6$ & $49.7 \pm 7.3^{*}$ & $67 \pm 8$ & $66 \pm 8$ \\
$71.5 \pm 7.9$ & $75.7 \pm 3.6$ & $67.8 \pm 7.3$ & $75.1 \pm 4.2^{*}$ & 74 & $81^{*}$ & $67.4 \pm 6.6$ & $75.3 \pm 4.4^{*}$ & $86 \pm 5.6$ & $85 \pm 3.6^{*}$ \\
& & & & & & & & $18 \pm 8$ & $19 \pm 7$ \\
\hline
\end{tabular}

show a decrease in oxygen delivery as shunt size increases, correlating with our previous studies, whereas the RVS models have an opposite tendency, being nearly steady for large conduits (Table 1 and Figure 5). For small shunt sizes, the arteriovenous differences are the same for both models. However, when larger conduits are examined, the mixed venous saturation increased only for the RVS model.

Comparing ventricular performance in terms of ejection fraction and mechanical efficiency (stroke work/total mechanical energy), the RVS models demonstrated higher values. Figure 2 (lower panel) illustrates the pressure-volume loops for the RVS model with a 5-mm conduit and the BTS model with a 3.5-mm conduit, which illustrates this behavior.

Two additional simulations for the RVS model with a 5mm shunt were carried out (Table 1). In one a value for the SVR of $10.8 \mathrm{~mm} \mathrm{Hg} \cdot \mathrm{m}^{-2} \cdot \mathrm{min}^{-1}$ was set, whereas the other had a value for the pulmonary arteriolar resistance of $4.6 \mathrm{~mm}$ $\mathrm{Hg} \cdot \mathrm{m}^{-2} \cdot \mathrm{min}^{-1}$. All other parameters were kept constant. Halving the SVR in the RVS model resulted in the following effects: decreased aortic diastolic pressure, increased pulse pressure, decreased $\mathrm{QP} / \mathrm{QS}$ ratio, increased $\mathrm{CO}$, decreased coronary perfusion pressure and coronary blood flow, increased oxygen delivery, slightly increased mixed venous oxygen saturation, and no change in conduit regurgitant flow. Doubling the pulmonary arteriolar resistance (to simulate an immediate postoperative scenario) in the RVS model resulted in the following: increased mean pulmonary artery pressure, slight decrease in the QP/QS ratio and $\mathrm{CO}$, increased conduit regurgitant flow, unchanged coronary blood flow and oxygen delivery, and decreased mixed venous oxygen saturation. Most of these changes are in accordance to those we observed for the BTS model, as previously reported. ${ }^{16}$

\section{Discussion}

The recent introduction of the RVS model has raised controversy regarding the optimal method of establishing pulmonary blood flow during the Norwood procedure for HLHS. There are a number of potential benefits, as well as liabilities, to this modification. However, there is also little doubt that the more established technique of the modified BTS has certain immutable hemodynamic disadvantages. In addition to the obligatory volume overload of the single ventricle, any shunt originating from a systemic artery has the potential to decrease diastolic blood pressure, with a resultant decrease in coronary artery blood flow. The combination of both of these consequences results in right ventricular dysfunction 

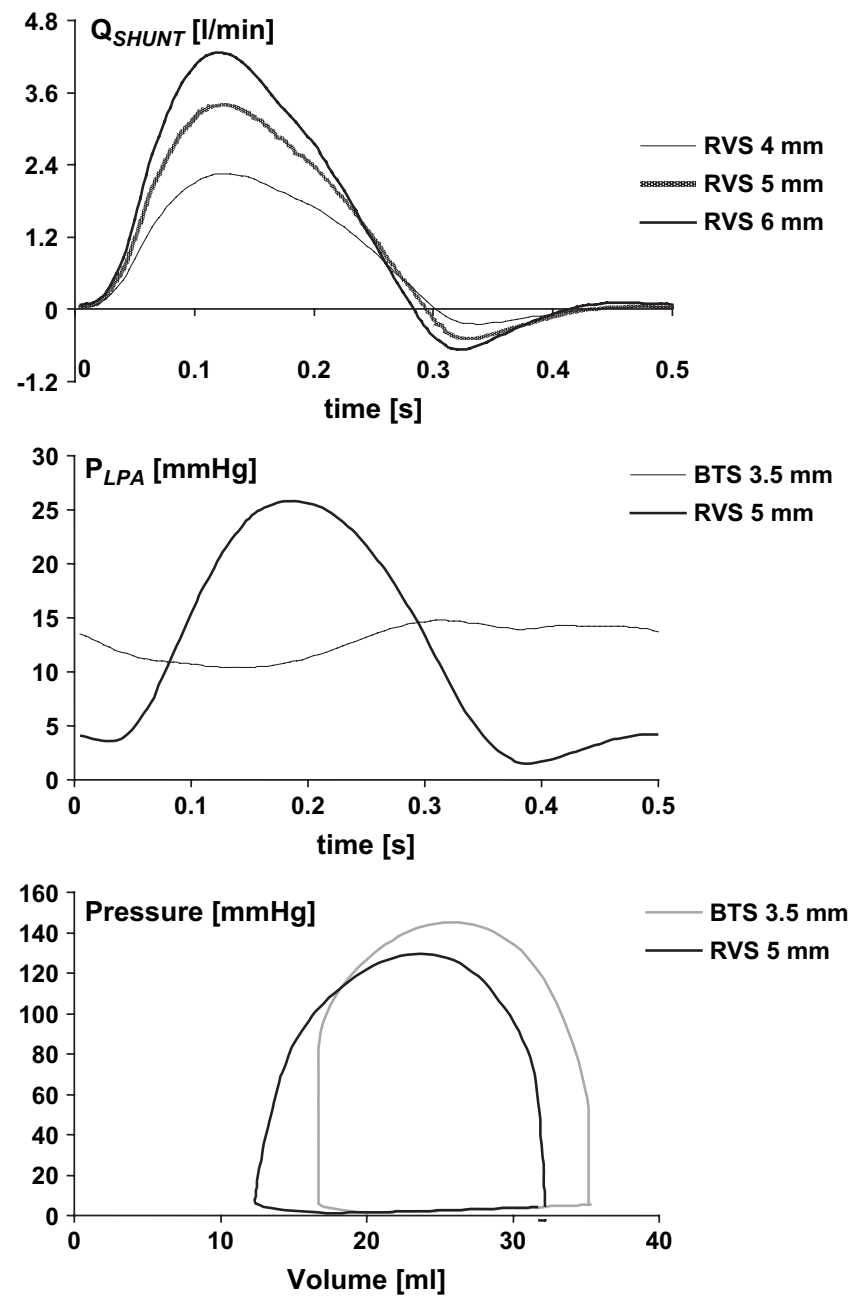

Figure 2. Shunt flow tracings in the right ventricle-pulmonary artery shunt (RVS) models (top); pressure tracings in the left pulmonary artery of the 3.5-mm Blalock-Taussig shunt (BTS) and 5-mm RVS models (middle); and pressure-volume curves for the 3.5-mm BTS and 5-mm RVS models (bottom).

and increased wall stress and leads to a vicious circle resulting in low CO. Without question, the size of the shunt has an important bearing on the hemodynamic outcome, and smaller shunt diameters have been used to limit pulmonary flow and diastolic hypotension. Furthermore, it is possible that coronary blood flow only becomes affected when relatively large modified BTSs are used. Thus when smaller conduits are placed during the Norwood procedure, diastolic blood pressure still remains above a certain minimal level, and coronary blood flow might be unaffected. The RVS removes the diastolic run-off inherent in a modified BTS but at the cost of an incision in the systemic right ventricle, the effects of which might not be apparent for many years. Thus the RVS modification might have a hemodynamic advantage when com- pared with large modified BTSs but perhaps less so or not at all when compared with the smaller BTSs.

Comparison of the RVS and BTS mathematic models highlights several differences between these operations that are fairly intuitive and therefore support the validity of the models. The BTS model exhibits lower aortic diastolic pressure and higher aortic pulse pressure than the RVS model, the RVS model exhibits lower pulmonary artery diastolic pressure and higher pulmonary artery pulse pressure than the BTS model, and the RVS model requires substantially larger shunt sizes to achieve pulmonary blood flow values similar to those with the BTS model. Higher aortic diastolic pressure should have a favorable effect on coronary blood flow in the RVS model; the consequences of more pulsatile pulmonary artery pressure and flow in the RVS model are less clear.

Of substantially greater interest are the effects predicted by the models that are not intuitive, particularly the effect of the RVS model on right ventricular afterload. Afterload would reasonably be expected to be lower in the BTS model because neoaortic diastolic pressure is substantially lower. However, the mathematic model shows that enough volume is ejected through the RVS before neoaortic valve opening that the ventricular wall stress is lower at similar pressures just because of the lesser right ventricular volume. Therefore compared with the BTS model, the right ventricle in the RVS model is afterload reduced. This feature of the RVS model permits a larger combined right ventricular output, which ameliorates the decrease in systemic oxygen saturation expected when pulmonary blood flow decreases to less than the systemic blood flow and also allows the end-diastolic volume of the right ventricle to be reduced, producing a slight reduction in the atrial pressure. Because pulmonary vascular resistance is identical in both models, it is the reduction in pulmonary blood flow and atrial pressure that results in the lower mean pulmonary artery pressure in the RVS model. Clinical confirmation of these predictions would strongly imply that the assumption of equal right ventricular function in the BTS and RVS models is correct. Identification of unexpected results like these, which then can drive hypothesis building for clinical investigations, is the strength of mathematic modeling, such as that reported in the current study.

The primary weakness of mathematic modeling studies is the inability to account completely for biologic adaptation. For example, after the Norwood operation, patients will have their BTSs or RVSs for several months, during which substantial physical growth and maturation are expected, yet the mathematic models do not account for adaptations that can occur during this period. Ventricular size might adapt well or poorly to the volume demands of the shunt, and there might be differences in both systemic vascular tone and ventricular function between patients receiving BTSs and RVSs that promote more optimal ventricular-vascular coupling for 


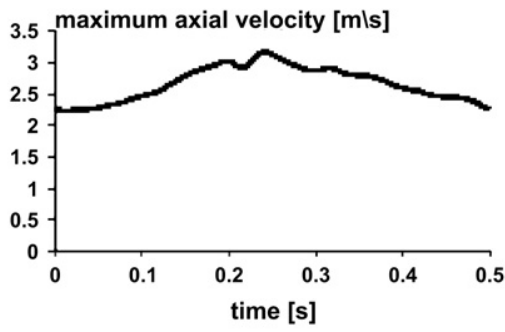

Figure 3. Velocity profiles along the shunt in the 3.5-mm Blalock-Taussig shunt model at 4 different instants of the cardiac cycle.
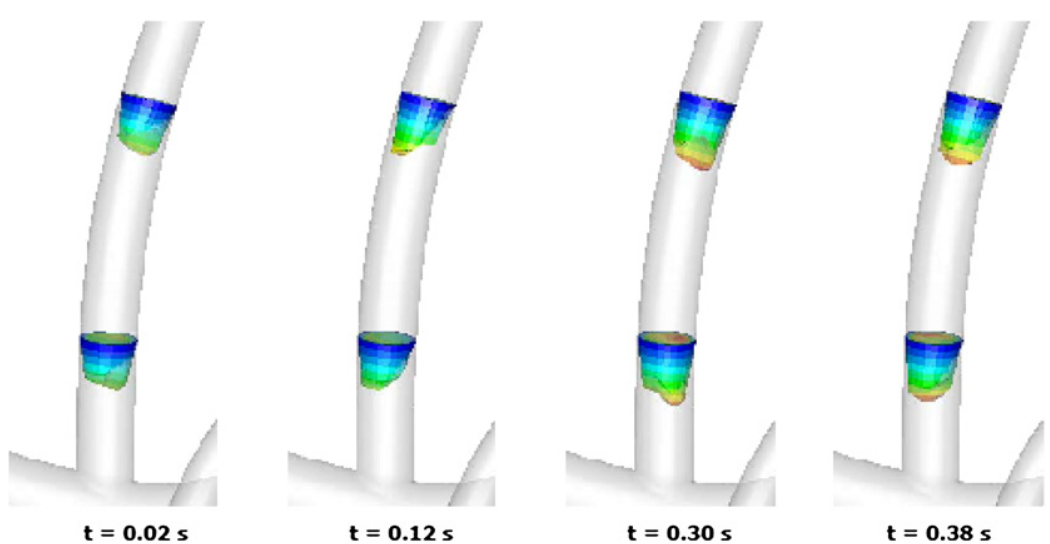

$\mathbf{t}=\mathbf{0 . 3 0 s}$

$\mathbf{t}=\mathbf{0 . 3 8} \mathrm{s}$

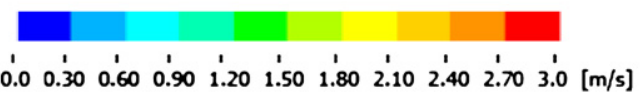

each group. Growth of the central pulmonary arteries during this phase is crucial, with little opportunity for rapid growth after second-stage conversion. ${ }^{20}$ It is clear that the flow and pressure characteristics of the pulmonary arteries differ between the RVS and BTS models, but it is unclear how these differences will be reflected in pulmonary artery growth and pulmonary vascular function. It easily can be supposed that the ventriculotomy required to construct the RVS will harm ventricular function to a certain extent and almost as easily supposed that the increased coronary perfusion pressure expected in patients receiving RVSs will enhance ventricular function, but only clinical observations can determine which factor, if either, has the dominant effect. Another important adaptive mechanism not accounted for in a mathematic model is that of coronary autoregulation. One of the major reasons for using an RVS is the notion, although unproved, that higher diastolic pressure results in improved coronary blood flow. However, the process of coronary autoregulation might render this issue untrue. It is equally possible that once a certain minimal level of diastolic pressure is achieved, there is little further variation in coronary blood flow. The RVS, like other proposed changes in the surgical and medical management of patients with HLHS, is designed to reduce early mortality after the Norwood procedure, as well as to limit intermediate-term mortality before second-stage conversion. It is important to remember that these goals, however worthy, are subordinate to the overall goal of achieving a high-quality Fontan palliation in the largest possible proportion of these patients. Therefore the final criteria by which the effect of the RVS must be judged include right ventricular systolic and diastolic function and pulmonary vascular anatomy and physiology at the time of Fontan palliation, as well as outcomes within the first 6 months of life.

\section{Conclusions}

The close correlation between predicted and observed data supports the use of mathematic modeling in the design and assessment of new surgical procedures and could become a useful addendum to randomized clinical trials. The results of these models still do not support superiority of one technique over the other in terms of flow dynamics and ventricular energetics. There is a need for including modeling of further interactions and adaptation, such as effects of oxygen on ventricular performance and changes of mechanical heart parameters. The clinical inferences drawn from these models suggest that for the BTS, shunt diameter is more crucial because larger shunts appear more detrimental. For the RVS, use of a valve might be unnecessary, whereas for both techniques, appropriate shunt sizes produce satisfactory oxygen delivery. 

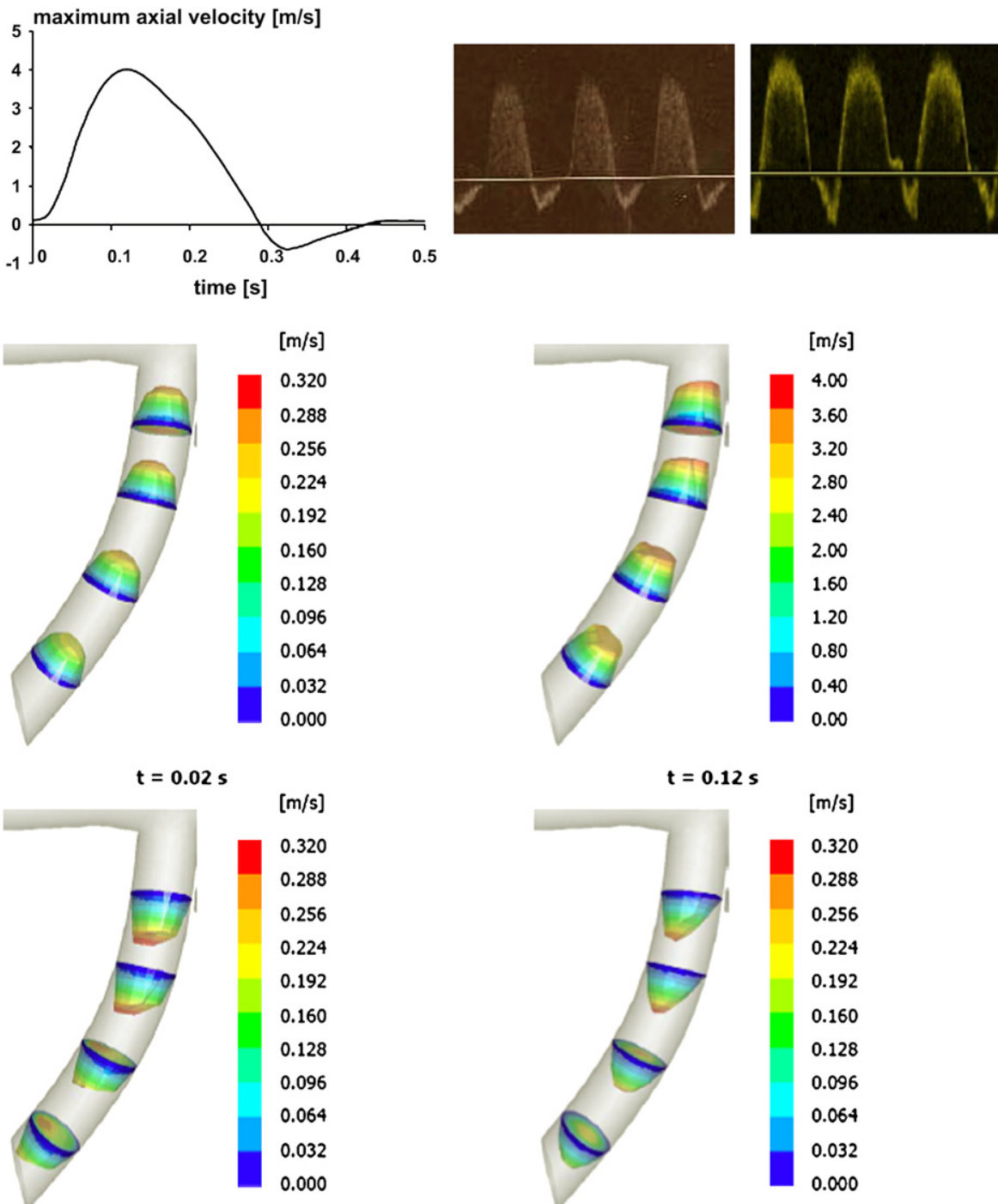

$t=0.30 \mathrm{~s}$
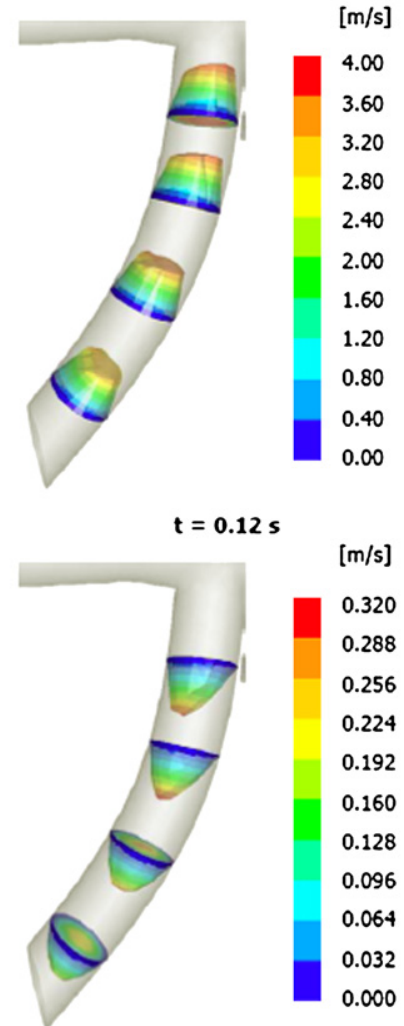

$t=0.38 \mathrm{~s}$
Figure 4. Velocity profiles along the shunt in the 5-mm right ventricle-pulmonary artery shunt (RVS) model at 4 different instants of the cardiac cycle. Velocity Doppler tracings in the proximal part of the right ventricular shunt of 2 patients are reported at the top right. The backward/forward velocity time integral ratio is about $\mathbf{2 0} \%$.

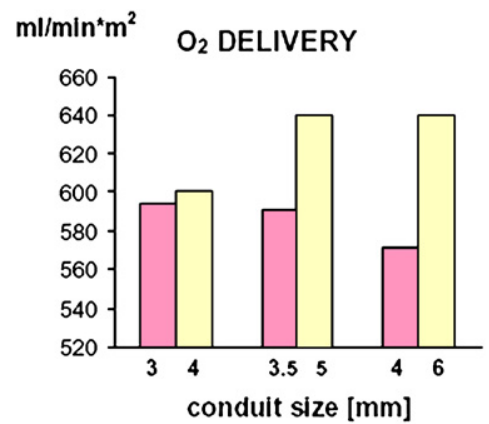

BTS

RVS

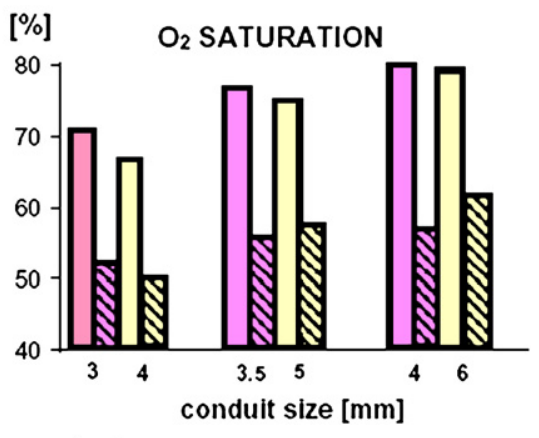

$\mathbb{N}$ MIXED VENOUS

ARTERIAL
Figure 5. Oxygen delivery (left) and arteriovenous oxygen difference (right) in the Blalock-Taussig shunt (BTS) and right ventricle-pulmonary artery shunt (RVS) models. 


\section{References}

1. Norwood WI, Lang P, Castaneda AR, Campbell DN. Experience with operations for hypoplastic left heart syndrome. J Thorac Cardiovasc Surg. 1981;85:511-9.

2. Imoto Y, Kado H, Shiokawa Y, Minami K, Yasui H. Experience with the Norwood procedure without circulatory arrest. J Thorac Cardiovasc Surg. 2001;122:879-82.

3. Sano S, Ishino K, Kawada M, Arai S, Kasahara S, Asai T, et al. Right ventricle-pulmonary artery shunt in first-stage palliation of hypoplastic left heart syndrome. J Thorac Cardiovasc Surg. 2003;126:504-9.

4. Maher KO, Pizarro C, Gidding SS, Januszewska K, Malec E, Norwood WI Jr, et al. Hemodynamic profile after the Norwood procedure with right ventricle to pulmonary artery conduit. Circulation. 2003;108:782-4.

5. Mair R, Tulzer G, Sames E, Gitter R, Lechner E, Steiner J, et al. Right ventricular to pulmonary artery conduit instead of modified BlalockTaussig shunt improves postoperative hemodynamics in newborns after the Norwood operation. J Thorac Cardiovasc Surg. 2003;126:1378-84.

6. Malec E, Januszewska K, Kolcz J, Mroczek T. Right ventricle-to-pulmonary artery shunt versus modified Blalock-Taussig shunt in the Norwood procedure for hypoplastic left heart syndrome-influence on early and late hemodynamic status. Eur J Cardiothorac Surg. 2003;23:728-33.

7. Pizarro C, Norwood WI. Right ventricle to pulmonary artery conduit has a favorable impact on postoperative physiology after stage I Norwood: preliminary results. Eur J Cardiothorac Surg. 2003;23:991-5.

8. Januszewska K, Kolcz J, Mroczek T, Procelewska M, Malec E. Right ventricle-to-pulmonary artery shunt and modified Blalock-Taussig shunt in preparation to hemi-Fontan procedure in children with hypoplastic left heart syndrome. Eur J Cardiothorac Surg. 2005;27:956-61.

9. Ghanayem NS, Jaquiss RD, Cava JR, Frommelt PC, Mussatto KA, Hoffman GM, et al. Right ventricle-to-pulmonary artery conduit versus Blalock-Taussig shunt: a hemodynamic comparison. Ann Thorac Surg. 2006;82:1603-9.

10. Laganà $\mathrm{K}$, Balossino $\mathrm{R}$, Migliavacca $\mathrm{R}$, Pennati $\mathrm{G}$, Bove EL, de Leval MR, et al. Multiscale modeling of the cardiovascular system: Application to the study of pulmonary and coronary perfusions in the univentricular circulation. J Biomech. 2005;38:1129-41.
11. Migliavacca F, Yates R, Pennati G, Dubini G, Fumero R, de Leval MR. Calculating blood flow from Doppler measurements in the systemic-topulmonary artery shunt after the Norwood operation: a method based on computational fluid dynamics. Ultrasound Med Biol. 2000;26:209-19.

12. Migliavacca F, Balossino R, Pennati G, Dubini G, Hsia T-Y, de Leval MR, et al. Multiscale modelling in biofluidynamics: application to reconstructive pediatric cardiac surgery. J Biomech. 2006;26: 1010-20.

13. Pennati G, Bellotti M, Fumero R. Mathematical modeling of the human fetal cardiovascular system based on Doppler ultrasound data. Med Eng Phys. 1997;19:327-35.

14. Pennati G, Migliavacca F, Dubini G, Pietrabissa R, de Leval MR. A mathematical model of circulation in the presence of the bidirectional cavopulmonary anastomosis in children with a univentricular heart Med Eng Phys. 1997;19:223-34.

15. Bove EL, de Leval MR, Migliavacca F, Gaudagni G, Dubini G. Computational fluid dynamics in the evaluation of hemodynamic performance of cavopulmonary connections after the Norwood procedure for hypoplastic left heart syndrome. J Thorac Cardiovasc Surg. 2003;126: 1040-7.

16. Migliavacca F, Pennati G, Dubini G, Fumero R, Pietrabissa R, Urcelay G, et al. Modeling of the Norwood circulation: effects of shunt size, vascular resistances, and heart rate. Am J Physiol Heart Circ Physiol. 2001;280:H2076-86.

17. Mantero S, Pietrabissa R, Fumero R. The coronary bed and its role in the cardiovascular system: a review and an introductory single-branch model. J Biomed Eng. 1992;14:109-16.

18. Quarteroni A, Veneziani A. Analysis of a geometrical multiscale model based on the coupling of PDE's and ODE's for blood flow simulations. Multiscale Model Simulation. 2003;1:173-95.

19. Ohye RG, Ludomirsky A, Devaney EJ, Bove EL. Comparison of right ventricle to pulmonary artery conduit and modified Blalock-Taussig shunt hemodynamics following the Norwood operation. Ann Thorac Surg. 2004;78:1090-3.

20. Mendelsohn AM, Bove EL, Lupinetti FM, Crowley DC, Lloyd TR, Beekman RH. Pulmonary artery growth patterns following the bidirectional Glenn procedure. J Thorac Cardiovasc Surg. 1994;107: 1284-90. 


\section{Appendix E1}

With reference to Figure E1, the basic equations that describe the oxygen transport from the lungs to the body are as follows:

$$
\begin{array}{cl}
Q_{p} \cdot C_{a r t} O_{2}+S \dot{V} O_{2}=Q_{p} \cdot C_{P V} O_{2} & \text { (equation 2.1) } \\
Q_{S} \cdot C_{a r t} O_{2}-C \dot{V} O_{2}=Q_{S} \cdot C_{V E N} O_{2} & \text { (equation 2.2), }
\end{array}
$$

where $\mathrm{C}_{\mathrm{art}} \mathrm{O}_{2}, \mathrm{C}_{\mathrm{ven}} \mathrm{O}_{2}$, and $\mathrm{C}_{\mathrm{PV}} \mathrm{O}_{2}$ are the arterial, venous, and pulmonary vein oxygen contents, respectively. Equation 2.1 describes the oxygen flow balance into the lungs and states that the pulmonary venous oxygen flow rate $\left(Q_{p} \cdot C_{P V} O_{2}\right)$ results from the sum of the oxygen flow rate into the pulmonary artery $\left(Q_{p} \cdot C_{a r t} O_{2}\right)$ plus the oxygen uptake in the lungs $\left(\mathrm{SVO}_{2}\right)$.

Equation 2.2 states that the oxygen flow returning to the heart $\left(Q_{S} \cdot C_{V E N} O_{2}\right)$ from the body is the oxygen flow rate (in milliliter of oxygen per minute) into the body $\left(Q_{S} \cdot C_{a r t} O_{2}\right)$ decreased by the body oxygen consumption $\left(\mathrm{C} \dot{\mathrm{V}} \mathrm{O}_{2}\right)$.

According to oxygen mass conservation for the steadystate condition, oxygen uptake in the lungs must be equal to oxygen consumption into the body:

$$
S \dot{V} O_{2}=C \dot{V} O_{2}
$$

(equation 2.3)

From equation 2.1, we obtain the oxygen arterial content $\left(\mathrm{C}_{\mathrm{art}} \mathrm{O}_{2}\right)$ as a function of $\mathrm{Q}_{\mathrm{P}}, \mathrm{C}_{\mathrm{PV}} \mathrm{O}_{2}$, and $C \dot{V} \mathrm{O}_{2} . \mathrm{C}_{\mathrm{PV}} \mathrm{O}_{2}$ is calculated on the basis of the assumed $\mathrm{Sat}_{\mathrm{PV}}$, which indicates the percentage of oxygen saturation of blood in the pulmonary veins.

The oxygen delivery $\left([\mathrm{mL}\right.$ of oxygen $\left./ \mathrm{min}] / \mathrm{m}^{2}\right)$ to the tissues is then obtained as follows:

$$
\mathrm{O}_{2} \text { delivery }=\frac{Q_{s} \cdot \mathrm{C}_{a r t} \mathrm{O}_{2}}{B S A}
$$

(equation 2.4).

The percentage of oxygen saturation of arterial blood ( Sat $\left._{\text {art }}\right)$ can be calculated as follows:

$$
\mathrm{Sat}_{\text {art }}=\frac{\mathrm{C}_{\text {art }} \mathrm{O}_{2}}{\text { Oxcap }} \cdot 100
$$

(equation 2.5),

where OxCap is the maximal oxygen capacity (in milliliters of oxygen per $100 \mathrm{~mL}$ of blood).

From equation 2.2, it is possible to evaluate the percentage oxygen saturation of the venous blood $\left(\mathrm{Sat}_{\mathrm{ven}}\right)$. 


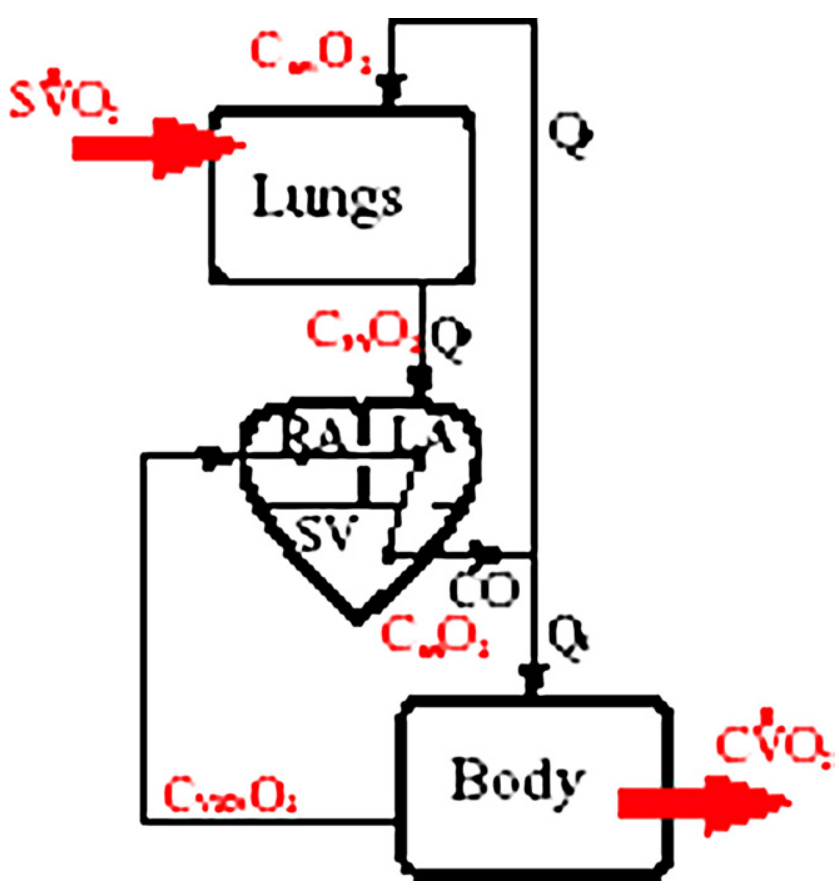

Figure E1. Oxygen model. RA, Right atrium; $L A$, left atrium; $S V$, single ventricle. 